George Rossolatos*

\title{
Rhetorical Transformations in Multimodal Advertising Texts: From General to Local Degree Zero
}

\begin{abstract}
The use of rhetoric in advertising research has been steadily gaining momentum since the 1980's. Coupled with an increased interest in multimodality and the multiple interactions among verbal, pictorial and auditory registers, as structural components of an ad filmic text, the hermeneutic tools furnished by traditional rhetoric have been expanded and elaborated. This paper addresses the fundamental question of how ad filmic texts assume signification from a multimodal rhetorical point of view, by engaging in a fruitful dialogue with various research streams within the wider semiotic discipline and consumer research. By critically addressing the context of analysis of a multimodal ad text in the course of the argumentation deployed by different approaches, such as Social Semiotics (Kress/Leeuwen 2001), Film Semiotics (i.e. Metz 1982, Carroll 1980, Branigan 1982), Visual Semiotics (i.e. Sonesson 2008; 2010, Eco 1972;1976;1986, Groupe $\mu$ 1992), Consumer Research (i.e. Mick/McQuarrie 1999; 2004, Philips 2003, Scott 1994), the relative merits of a structuralist approach that prioritizes the distinction between local and general degree zero, as put forward by Groupe $\mu$ (1992), are highlighted. Furthermore, the modes whereby rhetorical transformations are enacted are outlined, with view to deepening the conceptual tackling of degree zero of signification, while addressing its applicability to branding discourse and multimodal ad texts.
\end{abstract}

\section{Keywords}

Degree zero of signification; multimodal ad texts; structuralism; rhetorical transformations

\section{Introduction: Rhetoric and multimodal advertising texts}

Rhetoric is a metalanguage or a discourse on discourse (Barthes 1970). Rhetoric as a dominant discipline in the humanities lost ground to semiotics at the turn of the $20^{\text {th }}$ century. Yet, despite abundant criticism voiced against rhetoric's usefulness and analytical rigor, especially in the face of the increasing importance of visual versus verbal discourse in advertising communication, ongoing research has demonstrated that rhetoric is relevant more than ever, by virtue of its unique focus on mechanisms of persuasion. According to Abbott (1970: 195),

"Barthes, Todorov, Genette, Ricoeur, Group $\mu$, all portray the history of rhetoric as a long period of decline which culminates in rhetoric's "death." And yet all seem to suspect that they have exaggerated that death. The semioticians' own extensive accounts of rhetoric testify that rhetoric, in some form, did indeed survive into the twentieth century" (Abbott 2006: 318).

Barthes (1970: 195), even though proclaiming the end of rhetoric, came to the conclusion that it is indispensable, especially in the analysis of advertising imagery.

Rhetoric as an art of textual composition and mechanism for audience persuasion remains relatively underexplored in the marketing literature. Even more so when it comes to considering rhetoric as a strategy for analyzing ad textual signification and particularly from a multimodal perspective. To this end, taxonomical classifications of tropes and schemes that address both verbal

\footnotetext{
* George Rossolatos Department of English University of Kassel Mönchebergstraße 19, 34109 Kassel Germany grosolatos123@myway.com
} 
and visual modalities have been furnished by scholars, such as Durand (1970; 1987), Mick/McQuarrie (1992; 1996; 1999; 2003a; 2003b), Huhmann (2008), McQuarrie/Philips (2004).

In the context of proliferating interdisciplinary approaches, consumer researchers' interest in rhetoric has been steadily on the rise over the past twenty years. Ever since their seminal paper Reflections on Classical Rhetoric and the Incidence of Figures of Speech in Contemporary Magazine Advertising (1993) Mick and McQuarrie drew consumer researchers' attention to an immense gap between existing research methods that focus on decoding aspects of ad texts by target audiences and the ways whereby ad texts are configured rhetorically.

The concept of a rhetorical semiotic approach to advertising textuality is somehow paradoxical insofar as it presupposes that the two disciplines are opposed to each other, while they become artificially collated in an attempt to leverage distinctive practices, that is, the study of signs and the study of the persuasive effects of communication. Yet, they both feature methods of persuasion in their interpretive scope. According to Eco (1976), there is no signification without communication. Advertising semiosis occurs as an act of communication insofar as an advertising message is embedded in a communication process (cf. Jakobson 1985: 149-150). This is also echoed in Greimas's concept of semio-narrative structure ${ }^{1}$, which posits a theory of enunciation ${ }^{2}$ at the heart of the actantial model ${ }^{3}$. The role of advertising is to persuade a prospective consumer of the superior benefits of an advertised brand. Thus, the employment of a rhetorical analytical apparatus is indispensable from a semiotic point of view in addressing how an ad text may be structured persuasively with view to enhancing the credibility of its communication.

As advances in visual rhetoric suggest (Groupe $\mu$ 1992), rhetoric may address visual signification, and by extension brand visual signification, by furnishing a grammar that addresses multimodal transformations in terms of expressive elements and combinatorial rules.

\section{Multimodality in focus}

The term modality requires clarification as there are significant differences in its employment among different schools of thought in the semiotic tradition, such as Greimasian structuralism and the Sociosemiotic school of Kress and Van Leeuwen. According to Greimas (1966; Greimas/ Courtés 1979), modality is an aspect of the semio-narrative syntax of the actantial model (cf. fn 3). According to the semio-narrative syntax, what determines the process of conjunction between the actantial subject and the object of desire is the incidence of four modalities, viz. having-to

1 The semionarrative structure constitutes the intermediate level of the generative trajectory of signification (between the elementary structure of signification and the discursive structure), and consists of syntactic and semantic components. "Semionarrative structures consist of the entire set of virtualities the enunciating subject has at its hand [...] discursive structures correspond to the selection and ordering of these virtualities [...] semionarrative structures produce the plot [...] while discursive structures correspond to its staging and distribution" (Floch 2001: 113).

2 The model of enunciation was elaborated throughout Sémantique Structurale (1966), Du Sens I (1970) and Du Sens $I I$ (1983). As is the case with various concepts in the Greimasian model, enunciation is an umbrella term spanning various aspects of narrative structuration. Thus, enunciation (see Greimas and Courtés 1979: 123-128) may be defined as the general 'communication predicament' or the 'psychosociological context' allowing for the production of énoncés and at the same time as the virtual horizon of language allowing for its actualization in particular énoncés. The notion of virtuality is critical for understanding not only the function of enunciation, but also, at a more fundamental level, of making sense of how narrativity, as "various transformations resulting in (con) or (dis)junctions of subjects with their objects" (Courtés 1976:72) coheres with deep linguistic structures in the context of a deductive metalinguistic theory. The space of semiotic virtualities that enunciation is summoned to actualize is the locus of semio-narrative structures. This conceptualization of semio-narrative structures as horizon of actantial possibilities bears concomitantly on the conceptualization of the subject of enunciation or the human as actor. "The actants possess a metalinguistic status compared to actors" (Greimas 1966: 174), whereas the actor is a particular anthropomorphic rendition of an actantial structure in a particular narrative. As Greimas (1970: 166) stresses, "fundamental grammar, which is of a conceptual order, in order to be capable of producing manifest texts in figurative form, must assume at an intermediary semiotic level a non figurative, yet anthropomorphic representation".

3 "The actantial model is a tool that can theoretically be used to analyze any real or thematized action, but particularly those depicted in literary texts or images. In the actantial model, an action may be broken down into six components, called actants" (Hebert 2011: 71), viz. sender, receiver, subject, object, helper, opponent. (also see Greimas and Courtés 1979: 3) 
[devoir], being capable of [pouvoir], wanting to [vouloir] and knowing-how [savoir]. In effect, these four modalities are responsible for modalizing the actant's transitions among different states of being. Modalities are not predicates, but determinants of action and action lies at the heart of Greimas's actantial model.

Van Leeuwen approaches modality in a completely different direction. He argues that "the linguistic resources for expressing modality clearly go well beyond the grammatical system of modal auxiliaries" (Van Leeuwen 2005: 165). Modality, from a sociosemiotic perspective, "is the social semiotic approach to the question of truth" (Van Leeuwen 2005: 160).

From a sociosemiotic point of view, the concept of modality assumes a dual role, as it concerns both the social group that ascribes truth to a phenomenon, as well as the mode of representation in which this phenomenon is inscribed.

Regarding the first prong of this dual definition, Van Leeuwen draws on Halliday's functional linguistics in order to qualify modality as a proxy to truth value in terms of the relative frequency whereby an assertion is conceived by a social group as corresponding to states-of-affairs. "The more often what-is-asserted happens, or the more people think or say or do it, the higher the modality of that assertion [...] Thus, there is a close connection between degrees of representational truth and degrees of social obligation" (Van Leeuwen 2005: 163-165). Even though Van Leeuwen seems to be leaning towards a deontic theory of truth, a latent coherentism seethes into the picture while attempting to demarcate the modality of the visual modality (or the truth value of the visual modality, using both definitional prongs). Thus, based on the configuration of a visual sign according to variations in the means of visual expression, such as background, color saturation, modulation and differentiation, articulation of light and shadow (Van Leeuwen 2005: 167), viewers' judgments as to how real the visual sign is assume different modalities.

However, there is no one-to-one correspondence between configurations of a visual sign and modality judgments. In this respect, Van Leeuwen diverges from naturalist approaches to the signification of the visual sign (i.e. Saint-Martin 1987) that seek to anchor meaning in extra semiotic natural properties of the sign. "Instead, the modality value of a given configuration depends on the kind of visual truth which is preferred in a given context" (Van Leeuwen 2005: 168). This standpoint seems to be in agreement with the coherentist epistemological paradigm that undergirds Greimasian structuralism. For Greimas, truth or the theory of veridiction (Greimas's theory of truth) is instituted between the acts of communicative and interpretive doing (Greimas 1989a; also see Greimas/Courtés 1979: 417). Veridiction, according to Greimas, emerges as a contractual relationship between sender and receiver. What is exchanged in this contractual agreement is not just the value of the communicated object, but the truthfulness of the exchange value of the communicated object with the syntagmatic features of the surface narrative.

However, there is one crucial difference between the two perspectives, viz. the latent assumption made by the sociosemiotic perspective about the capacity of a social group to make a conscious judgment about the truthfulness of one or more configurations. This implies a literacy ${ }^{4}$ of the code of production of the visual sign and a mastery of the visual rhetoric as the backbone of the production of a particular configuration. The possession of such literacy by a social group is highly contestable, especially given that by definition the inventor of the configuration or sender/ addresser/destinateur possesses a «more immediate and articulated view of the underlying structure of the semantic system» (Eco 1976: 284).

4 The issue of code literacy in the context of visual rhetoric in advertising was raised by Scott (1994). Mick and McQuarrie (2003a: 197) stress that "figures contain within themselves instructions that they are to be treated differently than the surrounding text. Conversely, readers are knowledgeable about the conventions that govern how text marked in this way is to be read", which is highly contestable, not only in the light of its status as speculative remark, but also given that such a universal rhetorical literacy is by definition absent, unless the authors deem that every single member of an ad's audience may discern an anacolouthon or an antanaclasis in an ad film, even more so in the context of an advertising break's ad reel. 
Greimas also contends that the sender is in a hierarchically superior position compared to the receiver insofar as he manipulates the text (Greimas/Courtés 1979: 217). This juncture constitutes a qualifying difference between structuralism and sociosemiotics. For Greimas, the ascription of a truth value to such a visual configuration would be a matter of persuasion between the sender's communicative doing and the receiver's interpretive doing (based on actantial terminology). At the same time, he argues that persuasion is a semiotic act that is instituted in the context of the énoncé or the structural framework of the message.

In contrast, for Van Leeuwen persuasion seems to be dependent on pre-existing interpretive schemata, embedded in the judgmental structure of a social group. Moreover, "When 'meaning' has been attributed to something through the use of a schema, the meaning has a probabilistic quality which incorporates assumptions and expectations rather than an absolute quality defined by necessary and sufficient conditions" (Branigan 1992: 14).

However, unless some sort of visual literacy is presupposed that regulates the ability to decode the configuration of the visual sign based on the aforementioned variables, then what would amount to a conscious decoding is reduced to what Baudrillard defines as the 'passive magic' (Gaine 1993: 167) of the signs or the ability of the signs' configuration to condition the mode of its reception as being truthful in relation to the intended signified of the visual sign. In this sense, returning to the constitutional aspect of structural semiotics, veridiction is constituted in the act of enunciation based on the motivation of the sender. Thus, unless explicit visual literacy is demonstrated for a receiving social group from a sociosemiotic perspective, the truth of modality lies with the motivation of the sender who shapes the internal configuration of the visual sign.

The notion of modality is crucial for a semiotic approach to the ad filmic text as a plenum of multimodal elements. Barthes (1977: 41) remarked in The Rhetoric of the Image that text and image stand in a complementary relationship. "The words, in the same way as the images, are fragments of a more general syntagm and the unity of the message is realized at a higher level, that of the story".

What matters in a multimodal approach is not just the presence of different modalities in an ad filmic text, but also the interaction among modalities. Operations of rhetorical transformation impact directly on the relative importance of each modality (or mode, two terms that are often used interchangeably in the sociosemiotic literature) in shaping a surface discursive text. "One mode's potential to render 'meaning' can never be completely translated into that of another mode - and sometimes translation is downright impossible" (Forceville 2009: 4).

In the above cited collective work edited by Forceville (2009) multimodal interactions are discussed, as conflicting viewpoints are raised about the translatability of signs of the visual mode into the verbal one ${ }^{5}$. For example, Urios-Aparisi (2009: 100) in his essay on the Interaction of multimodal metaphor and metonymy in TV commercials claims that "the interaction of metaphor and metonymy and the processes of expansion and reduction ${ }^{6}$ between domains are similar to those in verbal language". The issue of whether the visual mode is isomorphic to the verbal was raised in Scott's (1994) paper on Visual advertising rhetoric, and findings are still inconclusive, especially in the multimodal advertising research field, which, as noted by Urios-Aparisi is still at

5 McQuarrie and Phillips (2004) argue for the complete autonomy of the visual sign and the irreducibility of visual to verbal rhetoric. The authors contend that picture is not speech and therefore visual rhetoric cannot be considered as merely a visualization of verbal figures of rhetoric.

6 The processes of expansion and reduction designate modes of interaction between metaphors and metonymies in the context of Lakoff and Johnson's concepts of source and target domains. Five types of interaction are distinguished (Urios-Aparisi 2008: 99), viz. (i) metonymic expansion of a metaphoric source, where the basis of the source of the metaphor is a metonymy (ii) metonymic expansion of a metaphoric target, where metaphor is the source and metonymy the target (iii) metonymic reduction of one of the correspondences of the target domain of a metaphor, where a metonymy in the target domain is responsible for reducing a metaphor in the target domain (iv) metonymic expansion of one of the correspondences of the target domain of a metaphor, where a metonymy in the target domain expands a metaphor in the source domain, and (v) metonymic expansion of one of the correspondences of the source domain of a metaphor, where a metonymy is responsible for expanding a metaphor in the source domain. 
an embryonic stage. However, with respect to the encoding process and in the context of a brand as motivated sign where multimodal elements assume similarity in a syntagmatic structure, the interaction among elements and their relative importance rests with the intentions of the brand owner. The syntagmatic ordering of multimodal expressive units confers similarity in terms of their iconic co-belongingness to the same brand. The juxtaposition or replacement of seemingly dissonant elements (at least based on non-brand specific background expectancies), such as a shoe in the place of a tie, assumes signification in the context of a brand owner's motivational structure that underpins a visual or verbo-visual configuration.

Despite the fact that current research in multimodal texts is largely embedded in cognitivist language (as in the aforementioned volume edited by Forceville) and not strictly speaking semiotic (at least from a structuralist semiotic point of view and particularly of Greimasian persuasion, which views psychological processes pertaining to the decoding process as extra-semiotic), key learnings are useful for a semiotic approach to the ad filmic text.

In this respect, the example employed by Urios-Aparisi (a 1986 ad filmic text of Renault) aims at displaying how a metonymic-metaphoric relationship between a featured athlete and a new car model are established. From a generic conceptual point of view, this exploratory focus is not new. The establishment of such similarities has preoccupied researchers in advertising semiotics since Barthes's (1977) inaugural reading of the Panzani pasta brand's advertising. What is new in this reading is the multimodal nature of the ad text (ad filmic text) and the conceptual approach employed in interpreting the rhetorical operations involved in its constitution. Let us explore, on the one hand, how argumentation deploys in the above example, while, on the other hand, to what extent such argumentation may be tackled from a structuralist semiotic point of view.

Urios-Aparisi (2009), in the aforementioned example, contends that "this metaphor is a clear case of personification", which is a standard statement in approaching advertising from a brand personification point of view. In Keller's (2008) terms, this personification tactic is an aspect of user or brand imagery.

In order to account for how brand personification is brought about Urios-Aparisi seeks recourse to techniques involved in the production of the concerned ad filmic text. Thus, the author emphasizes how an initial long-distance shot of the car model is followed by cross-cutting of shots between athlete and car model, which cross-cutting is coupled with close-ups on the athlete's shoes. By drawing on the aforementioned metonymical transfers between source and target domains, the author suggests that "the property that is metonymically cued in both domains is the power of the car's engine (and metonymically the whole car) and the power of the athlete who can jump very far" (Urios-Aparisi 2009: 101-102). Further interpretive constraints to the signification of the interaction of the elements that make up the aforementioned filmic syntagm or sequence are imposed by the verbal voice-over that aims to anchor the polysemous interplay among the visual signs. The cognitivist perspective employed in the analysis surfaces forcefully in two instances, viz. in the employment of the terms source and target of metaphorical mapping and in the employment of the term 'domain'.

From a structuralist semiotic point of view, the issue of 'experiential domain', as employed in the concerned paper by drawing on Lakoff and Johnson's (1980) terminology, viz. "metonymy is understood here as an internal mapping of a subdomain within the same experiential domain" is ambiguous insofar as it points to a clearly demarcated experiential domain prior to drawing a similarity with the context of the ad filmic text. This is contestable, as the cogency of the metaphorical similarity between car and athlete is not rooted in a clearly defined experiential domain, but in an encyclopedic universe (in Eco's [1976] terms) that determines the probability of the applicability of such a contrived similarity. The signification of the shoe / car part metonymy within this universe is not the outcome of a preexisting experiential domain, but of a bespoke inventio (in rhetorical terms). The probability of effectively decoding this metonymic invention depends on an inter-textual encyclopedic universe, which comprises cultural artefacts, such as magazines, cinematic films, as well as on the historical expressive inventory of the advertised brand. 
In terms of source vs. target of the metaphorical mapping, which are defined as "the target and source domains in a metaphorical relationship establish correspondences between different concepts in a way that does not happen in metonymy" (Urios-Aparisi 2009: 98) it may be counterargued, from a structuralist semiotic point of view, that the notion of symmetry is under-defined, as correspondences are drawn only on the surface level or the form of the plane of expression (see Appendix 1), in this case between athlete's shoes and car part, but not on the plane of content, in Hjelmslev's terms.

The assumption that the analogical relationship that is established in the context of a multimodal metaphor is symmetrical is purely speculative. Especially in the context of correlating a multimodal metaphor as composite expressive unit of two terms (shoes, car parts) with a concept of the content plane (i.e. /fast/ or /cutting edge design/) the notion of symmetry is not applicable. The relationship is purely contiguous and conventional. It may become arbitrary only insofar as the particular correlation as sign functive assumes the character of a cultural code that is instantly recognisable with minimal elaboration on behalf of a receiver. If the relationship was symmetrical there would be no need for attributing directionality to the filmic shots through the employment of the voice over.

The second point that merits, in my view, further discussion in the context of the aforementioned cognitivist account of multimodality is the divisibility of modes into submodes, that is, of a visual sign as a gestalt into further visual components, or as Urios-Aparisi (2009: 100) put it "the visual mode could be divided into several submodes such as color or movement", since "the submodes are building blocks of each mode" (Urios-Aparisi 2009: 100). This standpoint conflates signs as surface structural elements (i.e. color) with rhetorical operations of transformation (i.e. movement). Sequencing is not a structural element of the visual sign, but an operation whereby a string of visual signs assume signification, while being transformed through rhetorical operations. Sequencing of shots is analysable into modes, as rhetorical operations and modes of relatedness among elements, but not as component of an element. In short, elements of the plane of expression concern morphological aspects of an ad filmic syntagm, whereas sequencing concerns syntactical aspects, which are complementary, but not reducible to each other.

Further to these critical reflections on a cognitivist approach to multimodal ad filmic texts it becomes apparent that rehashing time-hallowed concepts (i.e. stressing that the verbal voice-over confers directionality to a sequence of visual shots as against the same claims in the context of the print ad, as endeavored by both Eco [1972] and Barthes [1977], where, instead of a voice-over, a printed tagline conferred directionality to the decoding process) does not address the heterogeneity of different modalities and the question raised by Scott (1994) as to whether there are inherent and a-contextual differences amongst modalities.

The preceding discussion was intended as prolegomena to the role of multimodality in a rhetorical semiotic account of the signification of the ad filmic text. In this context, a crucial contrast emerged, viz. that whereas modes of relatedness of elements on a surface discursive structure in the case of the verbal modality take place irrespective of any additional modes, in the case of the multimodal text that involves visual elements, such operations also concern the substance of the plane of expression as production techniques. Thus, the application of specific production techniques is crucial in shaping the filmic system as imaginary signifier in Metz's (1982) terms. "Devices such as the lap-dissolve foreground the essential unreality of filmic representation, since they represent nothing, yet are transformed by the desiring spectator into the "imaginary" of the diegesis" (Stam et al. 1992: 59). The same may be stressed about the verbal mode, both in oral and written form. For example, the incidence of pitch and intonation in the former and font type in the latter may transform rhetorically the content of an utterance, such as in the incidence of employing a high pitched voice, in an attempt to subvert the content of an utterance ironically, and the employment of a Gothic font type, in an attempt to add stylistic credence to an utterance. The sheer plethora of production techniques, in the case of visual discourse, overdetermines the ex- 
pressive potential of visual signs, both in terms of relatedness among visual elements, as well as in terms of their scope of rhetorical transformations.

\section{How multimodal ad texts signify through operations of rhetorical transformation: From general to local degree zero}

The systematic application of rhetoric in advertising and consumer research took off with Durand's seminal paper Rhétorique et image publicitaire (1970) (also included, in a short version, in English in Umiker-Sebeok 1987).

Durand was writing within a wider structuralist framework, while occasionally using Greimasian terminology (i.e. homologies, semes) even though explicitly recognizing his Greimasian influences on rare occasions and rather misleadingly. For example, Durand (1970: 73) stresses that semes are part of the signified, which holds in principle, insofar as Greimas replaced the signified with the semic microuniverse in Structural Semantics (1966), but did not mix terms in the sense of subsuming semes under the signified. In fact, the relationship between seme and signified in Greimas's metalanguage is tautologous, rather than hyponymic.

Durand defined the time-hallowed term rhetorical figure as a transformation from a simple to a figurative proposition and sought to map out this transformative process through a classification of classical rhetorical tropes as encountered in advertising discourse. "The different figures were classified according to two criteria: 1) the 'rhetorical operation': addition/suppression/substitution/exchange ${ }^{7}$; 2) the 'relation' between the variable elements: identity/similarity/difference/opposition $^{8 "}$ (in Umiker-Sebeok 1987: 295). This taxonomy is displayed in Table 1.

\begin{tabular}{|c|c|c|c|c|}
\hline $\begin{array}{l}\text { Operation } \\
\text { Relation }\end{array}$ & $\begin{array}{l}\text { A } \\
\text { Addition }\end{array}$ & $\begin{array}{l}\text { B } \\
\text { Suppression }\end{array}$ & $\begin{array}{l}\text { C } \\
\text { Substitution }\end{array}$ & $\begin{array}{l}\text { D } \\
\text { Exchange }\end{array}$ \\
\hline 1. Identity & Repetition & Ellipsis & Homeophore & Inversion \\
\hline $\begin{array}{ll}\text { 2. } & \text { Similarity } \\
- & \text { Of form } \\
- & \text { Of content }\end{array}$ & $\begin{array}{l}\text { Rhyme } \\
\text { Comparison }\end{array}$ & Circumlocution & $\begin{array}{l}\text { Allusion } \\
\text { Metaphor }\end{array}$ & Hendiadys \\
\hline 3. Difference & Accumulation & Suspense & Metonymy & Asyndeton \\
\hline $\begin{array}{ll}\text { 4. } & \text { Opposition } \\
- & \text { Of form } \\
- & \text { Of content }\end{array}$ & $\begin{array}{l}\text { Anachronism } \\
\text { Antithesis }\end{array}$ & $\begin{array}{l}\text { Dubitation } \\
\text { Reticence }\end{array}$ & $\begin{array}{l}\text { Periphrasis } \\
\text { Euphemism }\end{array}$ & $\begin{array}{l}\text { Anacolouthon } \\
\text { Chiasmus }\end{array}$ \\
\hline $\begin{array}{ll}\text { 5. } & \text { False } \\
\text { homologies } \\
\text { - } & \text { Double } \\
\text { meaning } \\
\text { - } & \text { Paradox }\end{array}$ & $\begin{array}{l}\text { Antanaclasis } \\
\text { Paradox }\end{array}$ & $\begin{array}{l}\text { Tautology } \\
\text { Preterition }\end{array}$ & $\begin{array}{l}\text { Pun } \\
\text { Antiphrasis }\end{array}$ & $\begin{array}{l}\text { Antimetabole } \\
\text { Antithesis }\end{array}$ \\
\hline
\end{tabular}

Table 1. Durand's taxonomy of rhetorical figures (1987: 296)

7 Durand defines the four rhetorical operations as follows: (i) addition denotes the addition of expressive elements to existing ones (this is the equivalent of adjunction in Groupe $\mu$ 's [1970] taxonomy of rhetorical operations) (ii) suppression denotes the subtraction of expressive elements from the existing expressive structure (the same term is used in Groupe $\mu$ 's [1970] taxonomy). Durand notes that it is more difficult to discern this operation, as it presupposes that the reader must first recognize that something is missing and then make conjectures about what is missing (iii) substitution denotes the substitution of one element for another (this is equivalent to Groupe $\mu$ 's operation of adjunction/suppression) (iv) exchange denotes the modification of relations among elements in an expressive unit. This is equivalent to Groupe $\mu$ 's (1970) operation of permutation.

8 Modes of relation are defined in a less clear-cut manner and are largely dependent on individual configurations between different operations and modes of relation that spawn distinctive figures. Thus, for example, the figure of repetition is a configuration of addition and identity; suppression and opposition yield reticence; substitution and difference yield a metonymy. 
Despite its limitations, Durand's attempt at furnishing a taxonomy of rhetorical figures, based on different modes of relatedness of expressive elements in a figurative relationship, was path-breaking. The short version of the initial Communications article (1970) that appeared in Umiker-Sebeok's collective edition Marketing Semiotics (1987) did not pay heed to the plethora of insights offered by Durand in the original article, especially those concerned with drawing parallels between psychoanalysis (Lacanian and Freudian) and rhetoric.

In the 1987 version, Durand's original argumentation was divested of its psychoanalytic theoretical underpinnings. In the original (1970) version, Durand laid explicit stress on the ambiguity of the very bases of classification, such as identity, difference and similarity. This classificatory ambiguity was attributed to the fact that rhetorical figurative discourse concerns the organization of the imaginary. Within the province of the imaginary, logical principles, such as the principle of identity, are liquidated, while bringing to the forefront the paradoxical coexistence in branding discourse of two dominant modes, the logical and the figurative. In this respect, Durand's theoretical approach resonates a fundamental Greimasian structuralist tenet, viz. that structures are responsible for channeling the imaginary, which is edified on the relationship between the as yet unformed ego and its surroundings, during the mirror phase (cf. Durand 1970: 73). As a result of this suppression, a crucial part of Durand's argumentation is missing from the 1987 version.

Three important limitations may be pinpointed in Durand's approach, from a branding point of view. First, an undue focus on brand positioning as motivational structure behind the manifest ad text. Second, an excess focus on surface structure for the extrapolation of the intended brand signification, without taking into account the plane of content. Third, not placing his analysis in a competitive context.

Again, such limitations should be read in the context of complementary research areas and by no means attain to overshadow Durand's analysis, which is of paramount importance as groundwork for ensuing research. However, a key criticism that may be voiced against the rationale underpinning Durand's analysis concerns the very function of rhetoric as transgression of normative patterns. Durand locates this deviation in an unexpected transformation of a simple proposition ${ }^{9}$. However, no further qualification is yielded about the base level against which a deviation may be discerned, in terms of audience expectations, a brand's existing language and a competitive context. Unless such a base level is clearly delineated (as endeavored by Groupe $\mu$ and their distinction between general and local or relative degree zero, as will be shown in due course), positing a generic 'simple proposition' as base level does not attain to bring forward the benefits of rhetorical transformations as operations whereby brand differentiation may be attained.

Forceville (1996: 57-59) pointed out the following limitations with regard to Durand's taxonomy:

- Many figures are explained in hardly more than a single sentence and with little precision.

- It is unclear what criteria were used to decide which figures of speech were to be included in the grid. Consequently, several transpositions from the verbal to the pictorial seem rather arbitrary.

- Although Durand nowhere explicitly addresses the matter, it transpires that there is no one-toone correspondence between verbal and pictorial figures, so that the neat grid of verbal figures has to undergo extensive modification to fit the pictorial examples.

- If and how pictorial tropes can co-occur is an issue left unexamined in the article.

As a result of Forceville's drawing on the short version of Durand's initial article appearing in Umiker-Sebeok's edition (1987), some of the criticisms formulated against Durand's taxonomy

9 "La figure de rhétorique étant definie comme une operation qui, partant d'une proposition simple, modifie certains éléments de cette proposition" (Durand 1970: 72). 
were actually tackled by Durand in the original Communications (1970) version, such as the criteria for the classification of the rhetorical tropes. In this respect, Durand stated explicitly that he employs as criteria of classification Barthes's distinction between metaboles and parataxes. Metaboles correspond to the paradigmatic level and parataxes to the syntagmatic; they comprise, respectively, tropes such as puns [jeux des mots], metaphors, metonymies and anaphora, ellipsis, anacolouthon and suspension (cf. Durand 1970: 72). Durand's departure from Barthes's initial classification consists in identifying the level of syntagm with operations and the level of paradigm with modes of relatedness, while also identifying the former with the plane of expression and the latter with the plane of content, in Hjelmslev's terms. Thus, what may be a valid criticism is not the lack of criteria of classification, but the validity of the suggested criteria.

In this respect, the structuralist classification furnished by Durand is not coupled with sufficient argumentation as to why modes of relatedness should correspond to the Hjelmslevian plane of content or the signified, since these operations concern the organization of surface discourse inasmuch as operations of rhetorical transformation. Durand stresses that modes of relatedness unite the variable elements of the advertising text. Despite the fact that modes of relatedness, strictly speaking in structuralist terms, concern both variable and invariant elements, if they concern the organization of units in a manifest brand discourse, then they correspond by definition to the plane of expression and hence the syntagmatic level. Thus, even though Durand did furnish criteria for the classification of tropes, these criteria did not address sufficiently the plane of content as already stressed.

Regarding Forceville's criticism with regard to single sentence definitions of tropes, this is due to the short version that appeared in Umiker-Sebeok's Marketing Semiotics, where the elaboration offered on different tropes in the original article is suppressed.

Regarding Forceville's third criticism that no a priori correspondence between verbal and visual rhetorical tropes may be posited, there is certainly sound methodological value in this fundamental question. The issue is whether such a question may be tackled deductively, and if yes against what criteria. If no correspondence may hold between the visual and verbal modalities based on the definition of each rhetorical trope, then either the tropes must be redefined or new types must be invented.

Durand's classificatory attempt is inductive, offering a rationale or, in Greimas's (1989b) terms, a reading grid, for matching visual syntagms against the background of existing definitions of tropes. The endeavor does not consist in effecting an overlap between the verbal and visual modalities, but in applying definitions of rhetorical tropes to the visual modality. The fact that rhetorical tropes crystallized through millennia of application in verbal discourse does not mitigate the tropes' extension to the visual modality. In this respect, Forceville's argument raises an important question, but not one that may be addressed directly to Durand's endeavor. This question concerns whether new rhetorical tropes should be defined in the context of the visual modality or existing tropes redefined. Durand explicitly pursues the second route: "In order to apply rhetorical figures to the visual domain, it was necessary to give more abstract definitions; however, by virtue of this abstraction, we now have at our disposal a tool of universal validity that is applicable to variable domains" (Durand 1970: 91).

By analogy, Peirce's tripartite classification of the sign has been applied to all sorts of modalities, without raising questions about the inherent differences of modalities. Ceteris paribus, if a picture may be approached as symbol, index or icon, then it follows that it may also be approached in relation to its function in an existing typology of rhetorical configurations. In any case, if the limitation pertaining to the potential non-applicability of verbal tropes to the visual domain holds true, then it would also hold in the case of Forceville's application of the definition of metaphor as furnished by Lakoff and Johnson directly to the pictorial modality.

Forceville's fourth point concerning the possible co-occurence of different pictorial tropes is also debatable. If such a question is raised, then it must be complemented by how invariant elements may recur. In the context of motivated brand discourse as ad text, rhetorical operations are 
critical in channeling brand signification. The co-occurence of different tropes concerns the plane of expression or the ability to read pictorial syntagms as effects of rhetorical operations. However, both on intra, as well as inter ad execution levels, these operations function with the aim of correlating elements of the plane of expression with elements of the plane of content or brand image attributes as parts of a brand identity system. The effective constitution of brand identity depends on the recurrence of invariant brand elements on both planes. Thus, what is validly pointed out by Forceville should be extended to the dimension of how invariant elements recur in the light of rhetorical transformations, which may function not only positively as reconfigurations of surface discourse features, but also negatively, as masking invariant elements that are necessary for the maintenance of brand identity, thus potentially rendering them unrecognisable.

Last, but not least, it should be stressed that Durand's principal aim did not rest with furnishing a taxonomy of rhetorical figures. His main goal was to find ways whereby the process of creative development of advertising executions could be automated. His intention was to coin a universal formal rhetoric, applicable to all modalities, capable of accounting for all sorts of semantic transformations. In his view, rhetorical operations are responsible for how signs signify not only in natural language, but also in scientific discourse. In this respect, he sought to establish, one might say, a pan-rhetorical outlook towards signification. In pragmatic terms, and from a branding point of view, Durand's approach is revelatory with regard to how a system of brand values, as reflected in brand image attributes, is transformed into creative elements. From this point of view, Durand's contribution has been significantly undervalued by authors who focused partially on details of a taxonomic model, which are certainly important, but not the focal point of Durand's study. As a matter of fact, the focal point of Durand's formal rhetoric (which resembles on a programmatic level Groupe $\mu$ 's vision of a global multimodal rhetoric) consisted in yielding an account of a system of signification that prioritizes operations as relational elementary units. "The fundamental elements of this system are not defined by their substance, but only by their relations. On the one hand, the system defines how global relations (between propositions) may be deduced from base relations (between elements). On the other hand, it defines how such diverse transformations may be applied to relations (rhetorical operations)» (Durand 1970: 92).

In an attempt to further develop Durand's taxonomic approach of rhetorical operations/figures, Mick and McQuarrie (1996) redefined rhetorical operations according to four different classes, viz. repetition, reversal, substitution, and destabilization. Their taxonomy (McQuarrie/Mick 1996: 430-43) included some of the tropes not mentioned in Durand's taxonomy (i.e., irony, as noted by Forceville 1996).

The taxonomy of schemes and tropes is structured on a continuum of increasing complexity, from simple schemes to complex tropes ${ }^{10}$. Moreover, an underlying assumption made by the authors is the existence of a positive symmetrical relationship between complexity of figuration and ad content recall. This assumption has also been endorsed by various scholars, working both within a verbally and a multimodally oriented perspective (i.e. Messaris 1997) in consumer research and partially confirmed through primary research. "Metaphorical style of rhetoric and visual argumentation, both of which can be characterized as implicit argumentation, are likely to increase audiences' cognitive elaboration when they process the message, which may lead to greater persuasion" (Jeong 2008: 60). However, such findings are hardly generalizable. As previously pointed out, highly figurative discourse may function positively in terms of recall, but also negatively. As an example, Kenyon and Hutchinson (2007) who applied Mick and McQuarrie's typology of rhetorical operations to the alcoholic drinks category and particularly to advertising of Absolut vodka, concluded that the more devious the advertising imagery the more consumer associations tended to vary, hence the greater the threat in maintaining a uniform brand identity structure. This finding is compounded by further research (Katelaar/Van Gibsergen 2005; Van Mulken et al.

10 "Schemes are excessively regular or ordered, whereas tropes are irregular or disordered" (McQuarrie and Mick 2003: 200). 
2008; Van Mulken et al. 2010), which concludes that attitudes towards more complex ads are less favorable than attitudes towards less complex ads.

The complexity of a rhetorical mode cannot be determined universally, but is dependent on a brand's and a category's communicative inventory. In a highly abstract product category regarding image attributes and values, such as alcoholic drinks, a metaphor may be as simple as a pun in a more functional category, such as surface cleaners. This point seems to be endorsed by McQuarrie and Mick who avowed in a later elaboration of their ongoing argumentation that «frozen metaphors (eg. a tire that hugs the road), which have become clichés are no longer rhetorical definitions» (McQuarrie/Mick 2003: 198). However, it may counter-argued that metaphors are still metaphors, albeit «dead», that is used to such an extent as to assume arbitrary status as against motivated and hence close to be literalized. The determination of the level of complexity of a rhetorical mode depends on the category at hand and the imagery established through the category brands' communication.

Furthermore, Mick and McQuarrie do not address Forceville's above mentioned criticism concerning the correspondence between visual and verbal rhetorical figures. They are working on the hypothesis of a latent correspondence, in the same vein as Durand's approach. The same criticism that was oriented towards Durand's overreliance on the plane of expression as against content may also apply in the case of Mick and McQuarrie, who claim that «the deviation occurs at the level of form rather than content, and the deviation conforms to a template that is invariant across a variety of content and contexts» (McQuarrie/Mick 1996: 425). The same point is reiterated by Philips (2003: 297).

The point that may be raised at this juncture concerns the criteria against which a rhetorical deviation may be gauged. If we make the conceptually and practically valid assumption that intended positioning, as a brand's depth grammar, in Greimasian terms, is the point of departure of an ad text's signification, then deviations should be considered at the level of a correlation between the planes of expression and content, and not merely on the level of an ad text's deviation from some sort of expressive mean score. Hence, rhetorical deviations do not concern merely elements of the plane of expression, but primarily the ways the addition, suppression, substitution or permutation of new expressive units affect brand identity as correlational patterns between the plane of expression and the plane of content.

In the light of the above, McQuarrie and Mick (1996), in line with Durand, underemphasize the plane of content at the expense of an expressed focus on the plane of expression. This is coupled with a unilateral ascription of syntagmatic combinatory responsibility to schemes, as against tropes. In Figure 1, where they define different schemes and tropes based on a universally applicable complexity continuum, a paradigmatic function of selection is attributed to rhetorical tropes, which may be contested insofar as both schemes and tropes are responsible for the organization of surface structures as advertising discourse. 


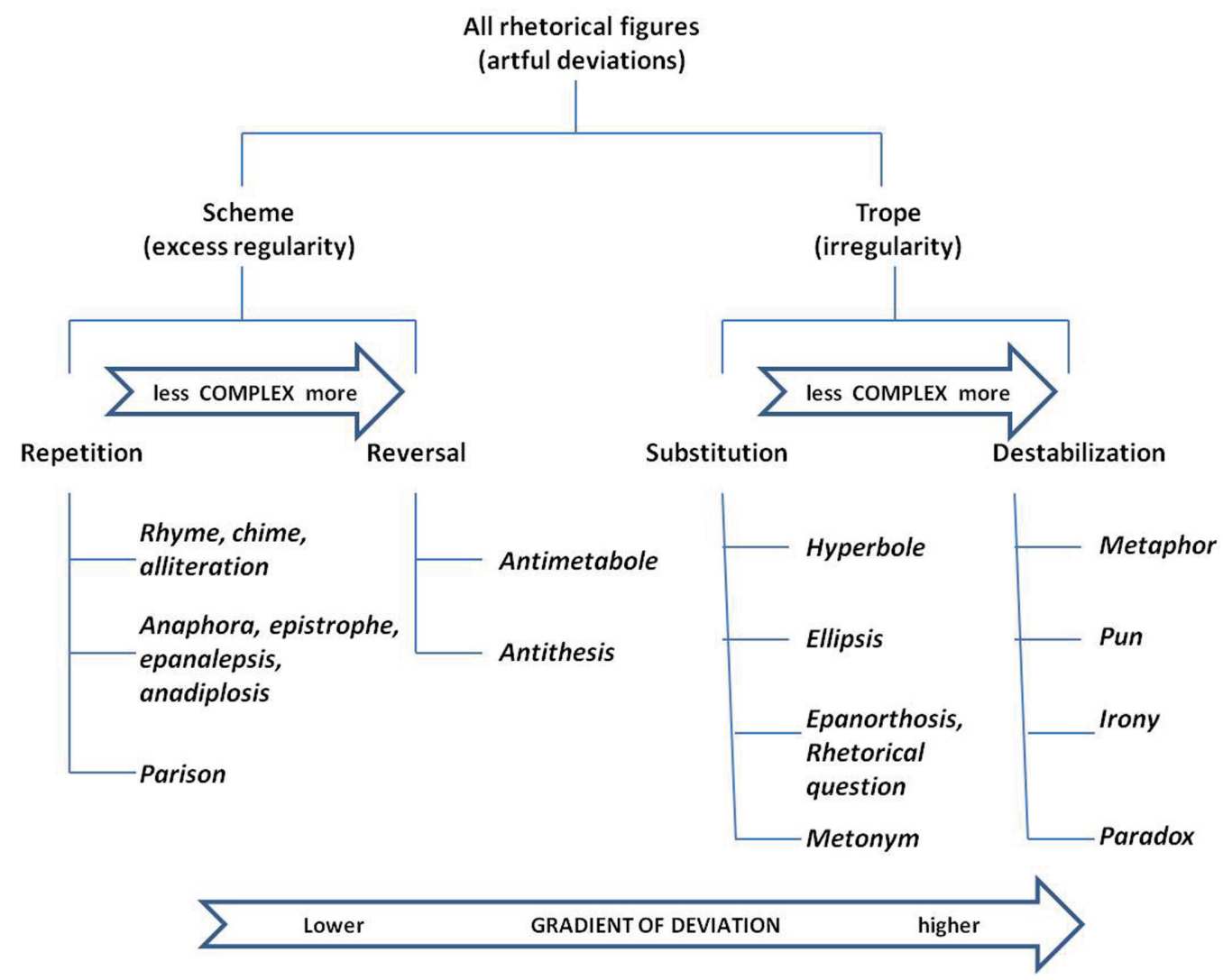

Figure 1. Taxonomy of rhetorical figures in advertising based on their level of complexity (McQuarrie/ Mick 1996: 426)

McQuarrie and Mick (1996) stress that the deductive validity of their taxonomy is in need of validation, which was also the case with Durand's taxonomy ${ }^{11}$. This validation, they argue, will coevolve with the ongoing application of the model in concrete empirical instances. In addition, the taxonomic model is a useful heuristic mechanism for organizing surface discursive patterning, and by no means a causal blueprint determining what effects will be produced with any combination of rhetorical figures. Furthermore, as Mick and McQuarrie emphasized in a paper that appeared in Scott and Batra's collective edition Persuasive Imagery (2003):

\footnotetext{
"The point to be emphasized is that when a research approach focuses primarily on the response of the human system, with or without an emphasis on personal or situational moderators, it tends to pay relatively less attention (if any) to differentiations within the set of visual elements. In contrast, the distinctive contribution of rhetorical and semiotic approaches is precisely to deepen our understanding of how best to parse and comprehend the role of particular visual elements within the ad system. Rhetoric and semiotics are text-centered disciplines (McQuarrie 1989; Mick 1986). As such, they make relatively simple and straightforward assumptions about the human system, concentrating instead on the development of elaborate structures that can be used to differentiate types of visual content in advertisements" (Mick/McQuarrie 2003: 192).
}

This crucial comment, which lays bare a latent structuralist scientific attitude, largely informs the authors' ongoing contributions to rhetorical research in advertising. Consequently, the authors make a call for a return to the text, as the province of rhetoric and semiotics, which, coupled with ongoing advances in consumer research concerning how ads are processed, may yield a rich picture of how ad signs signify. 
By raising the recurring question as to whether there are inherent differences between visual and verbal signs, Scott brought style to the limelight of attention as a key organizing principle among various advertising executions. Scott argues for the dissociation of advertising pictorial signs from any iconic dimension, while reconstituting their signifying function, and by implication the rationale behind their ordering, to the symbolic dimension (tacitly applying Peirce's tripartite distinction of signs into symbols, icons and indices) that is governed by convention.

Scott's approach is in line with Eco's (1976) conventionalist ${ }^{12}$ perspective of iconicity. Mannerism in terms of a visual's color gradation/saturation and visual elements' arrangement combine with normative expectations on behalf of the audience and the intended effects behind the elements' rhetorical configuration. "Through variations in the selection of viewpoint, style and context, as well as through references to or interactions with other texts and systems, these images become capable of highly sophisticated rhetorical tasks" (Scott 1994: 264).

Given that ad decoding is laden with high degrees of subjectivism ${ }^{13}$, based on the reader's cultural repertoire, intentions, experience and that, especially in the case of pictorial and even more so auditory signs, it is impossible to coin an exhaustive set of configurational rules; yet, it is possible to systematically describe (and in part admit of a relative prescriptive status as part of a dominant code) certain stylistic manipulative devices. Scott attempts to provide generic guidelines or key variables on which stylistic decisions are usually and hence must be made, however these do not constitute a theory of visual rhetoric, but empirical stylistic guidelines. Scott continued to cling to her initial argumentation in the review of rhetorical semiotic approaches that appeared in the collective work Persuasive Imagery, by avowing that "although the system remains pictorial, it is no longer based on resemblance but on shared cultural understanding or convention" (Scott 2003: 20). While pursuing a more holistic visual rhetorical approach to advertising signification (and the same holds for Forceville who addresses multimodality along the entire spectrum of Jakobson's communication model), she points out that historical-contextual analysis of the relationship between a visual and its context is conducted in order to identify the forces that contribute to, or work against a visual's purpose. "One consults external sources in search of information about the rhetor, the audiences exposed to the visual, and the persuasive forces, including other rhetorical messages, operating on the visual" (Scott 2003: 34), thus laying claim to extratextual and inter-textual forces operative in a particular visual text or elements of codes, in Eco's terms. In marketing terms, such a holistic outlook to visual semiosis attains to address competitive dynamics, but also elements of the external marketing environment that are crucial in order to make sense of the selection and combination of visual elements.

As noted in the introduction to this section, rhetoric related marketing advances have not been keeping pace with advances in the fields of visual and film semiotics that have been placing rhetoric at the heart of their approach.

Groupe $\mu$ 's attempt to coin a new general rhetoric that appeared during the late seventies / early eighties, as a unique blend with semiotics, was met with enthusiasm from academic circles. This attempt was complemented by an extension to the field of Visual Rhetoric and the bespoke Traité du Signe Visuel (1992), which put the visual sign in perspective under the rubric of a theory of visual rhetoric, informed by structuralist semiotics, as well as mingling this approach with psy-

12 Eco's conventionalist approach to iconicity is particularly evident in his so-called early period. Sonesson stresses that Eco's views on iconicity have varied throughout his writings, while pointing to at least three different sets of arguments, each one sharing different presuppositions and different degrees of conventionalism. "At the first stage, Eco $(1968 ; 1970 ; 1972)$ is basically concerned to show that iconic signs (the basic example being pictures) are similar to linguistic signs in being conventional and analysable into features; at the second stage $(1976 ; 1978 ; 1984 a$, b), he abandons the idea of feature analysis but wants to dislocate the required similarity sideward, into some kind of proportionality. In the final stage, however $(1997 ; 1998 ; 1999)$, he seems to give up almost everything he has so far believed in, and, while retaining a tiny part for convention, basically goes to the other extreme, making all icons into mirrors affording a direct view onto reality" (Sonesson 2008b: 2-3) .

13 «Apprehending and interpreting stylistic characteristics of this sort depend heavily on the ability and skill of the interpreter» (Mick/McQuarrie 2003a: 195) 
chological approaches to the formation of visual perception. Groupe $\mu$ 's approach is relevant, not simply from a typological point of view regarding new criteria for the classification of rhetorical figures, but also from a conceptual point of view, especially regarding the operations of rhetorical transformation.

In the following paragraphs I will point out aspects of Groupe $\mu$ 's theory of visual rhetoric and discuss its potential applicability to multimodal ad filmic texts. Let it be noted that the main field of application of Groupe's approach was the static picture (and plastic figures), but not the ad filmic text (with the exception of a short reference to Eisenstein's montage in Rhétorique Générale [1970]), which does not mitigate the theory's applicability to the latter (certainly with qualifications).

According to Groupe $\mu$ (1992: 257), the fleshing-out of a complete program of a rhetoric of visual messages based on a program of a general rhetoric calls for a procedure that consists of the following steps:

1. Elaboration of rules for segmenting the unities that make up the object of rhetorical operations on both iconic and plastic levels.

2. Elaboration of rules for rhetorical reading of these messages [énoncés].

3. Description of the rhetorical operations operative in these messages [énoncés].

4. Description of the different possible relations between perceived and conceived degrees that will result in a taxonomy of figures.

5. Description of the effects of these figures.

Earlier in this section, in the context of discussing Forceville's arguments against Durand, the issue of whether a set of new rhetorical figures is called for or a redefinition of existing ones in the light of visual signs was raised. Durand evidently opted for a modification of the definitions of existing tropes, as already pointed out. Groupe $\mu$ opted for both options. Starting with their groundwork Rhétorique Générale (1970), a new set of typologies of rhetorical figures was furnished, viz. metaplasm, metataxis, metasememe, and metalogism. Metaplasms are figures that act on sounds or graphic aspects of language. Metataxes are figures that act on the structure of the sentence. Metasememes are figures that replace one seme, or unit of meaning, with another. And, finally, metalogisms are figures of thought that modify the logical value of sentences. Each 'metabole' or figure is also categorized into one of four different operations: suppression, addition, suppressionaddition, and permutation.

Groupe $\mu$ 's contribution to rhetorical semiotics, though, is not exhausted in the provision of new classification criteria and the redefinition of rhetorical operations. Their semiotic rhetorical theory responds to the above pointed out limitations of rhetorical research in the advertising related literature, which allegedly is confined to the plane of expression, by opening up the analytical scope to the plane of content. Moreover, it relativizes the function of rhetorical figures' artful deviation, which lies at the heart of Mick and McQuarrie's (1996), Scott's (1994), Phillips' (2003) definitions of rhetoric, by introducing a sharper distinction between absolute and relative degree zero of deviation. Whereas deviation by the aforementioned authors in the consumer research literature is conceptualized by comparison to expectations embedded in some sort of generically conceived natural language, for Groupe $\mu$ deviation is a highly situational phenomenon. Hence, absolute degree zero as an acontextual non rhetorical figurative level is an ideal. What is operative on a practical level is a relative degree zero of configuration, which may be discerned by examining the context of an énoncé, 
Absolute and relative ${ }^{14}$ degrees zeros are also described by Groupe $\mu$ in terms of Eco's (1976) levels of codedness ${ }^{15}$, while replacing overcoded signs with strongly coded and weakly coded ones with undercoded. The more overcoded or strongly coded a visual sign, the more it approximates an absolute degree zero. In contrast, the more undercoded, or weakly coded the more it approximates a relative or local degree zero.

The determination of level of codedness in terms of a sign's distance from a degree zero of signification is crucial as it constitutes a ground rule for the entire theory of visual rhetoric. The level of codedness of a visual sign also attains to address the sign as sign functive or correlation between planes of content and expression, in Eco's (Hjelmslev's) terms, rather than being confined at the level of expression. This point of departure also constitutes the crux of Groupe $\mu$ 's hybrid rhetorical semiotic approach, viz. the employment of the semiotic conception of the code as the fundamental rubric under which the classification of rhetorical operations may be effected. The same point of departure was assumed by Eco (1976), who posited a theory of the Code as the necessary condition upon which a theory of the production of signs may be edified.

The general degree zero is furnished by the prior knowledge of the code. The local degree zero is furnished by the isotopy of an énoncé. Groupe $\mu$ uses the term isotopy in a Greimasian sense, as the grounding of an idea in a totality of meaning or an entire text. The homogeneity of a visual text is maintained not by the logical chaining of sequences, but by a chain of signifieds. Groupe $\mu$ thus posits at the center of its theory of visual rhetoric the need for addressing both expression and content planes, while attempting to account for how coherence emerges in a visual text. The local degree zero is the element pertaining to such a territory of an énoncé, by virtue of a structure that is particular to that énoncé. This is the case where visual plastic énoncés engender internal regularities. They also stress explicitly that isotopy is a very useful concept, especially for advertising, among other discourses, which are characterized by polysemy and interpretive openness. "It is the local degree zero, as inferred isotopically, that is responsible for producing rhetoricity, the general degree zero being nothing more than its condition of existence" (Groupe $\mu$ 1992: 263).

For Groupe $\mu$ (1992: 259) the key features that make up a strongly coded sign include the following:

1. The segmentation of the planes of expression and content is quite clear.

2. The relation between the unities of each plan is strongly stable.

3. These sign systems may be described outside of the énoncé, with the aid of a vocabulary and a syntax.

14 I am translating 'général' into absolute and 'local' into relative in order to emphasize the contextual dependence of each type of degree zero. Whereas a deviation from an absolute degree zero is determined by reference to a strict system of rules (i.e. standard grammar), a deviation from a local degree zero is determined relative to a highly contextual pattern of regularities that may be discerned in a text.

15 Overcodedness is tantamount to the closure of meaning or to the maximally elaborated coded interpretation of a constellation of signs. "The operations of overcodedness, when completely accepted, produce an s-code. In this sense overcoding is an innovatory activity that increasingly loses its provocative power, thereby producing social acceptance" (Eco 1976: 134). Overcodedness is a necessary condition for the recognition of the interpretive stability of sign-constellations and it operates as a stabilizing social force or a dominant social logic. "Undercoding may be defined as the operation by means of which in the absence of reliable pre-established rules, certain macroscopic portions of certain texts are provisionally assumed to be pertinent units of a code in formation, even though the combinational rules governing the more basic compositional items of the expressions, along with the corresponding content units remain unknown" (Eco 1976: 135-136). Extracodedness lies between over and undercodedness and includes the extra semiotic and uncoded determinants of an interpretation. The as yet unfamiliar to a code elements are potentially inscribed in a given code (or manage to institute a wholly new one) primarily through a play of inferential probabilities, which correspond to the logical operation of abduction. 
In short, the relationship between the elements of the plane of expression and the elements of the plane of content in the incidence of a strongly coded sign is clear, stable and independent of the contextual contours of an énoncé.

In contrast, the key features that make up a weakly coded sign include the following:

1. Fluid formalization of the relationship between the two planes.

2. The link is established by ratio difficilis that is through an abductive rationale that draws on minimal and highly situational inferential conditionals.

3. No content is furnished to the receiver by a lexicon that preexists the énoncé.

\begin{tabular}{|c|c|c|c|c|}
\hline Semiotic type & I. & $\begin{array}{l}\text { Segmentation of } \\
\text { unities }\end{array}$ & II. & $\begin{array}{l}\text { Relationship } \\
\text { between } \\
\text { expression and } \\
\text { content }\end{array}$ \\
\hline Strongly coded & \multicolumn{2}{|c|}{ Clear } & \multicolumn{2}{|c|}{ Stable } \\
\hline Weakly coded & \multicolumn{2}{|c|}{ Unclear } & \multicolumn{2}{|c|}{ Unstable } \\
\hline
\end{tabular}

Table 2. Four types of relationship between expression and content (Groupe $\mu$ 1992: 260)

Four types of relationship between expression and content ensue from the above classification, as follows:

1. Strongly formalised expression + strongly formalised content $=$ stable link (example: most recognizable brand logos)

2. Strictly formalised expression + weakly formalised content $=$ unstable link (e.g. plastic signs)

3. Weakly formalised expression + strongly formalised content $=$ unstable link

4. Weakly formalised expression + weakly formalised content $=$ unstable link

Groupe $\mu$ also places the notion of 'distance' in the frontline of enquiry about the modes of figurative signification. The degree of figurativity of a rhetorically constituted visual sign hinges on the distance from a local degree zero. However, this sort of distance is highly speculative and difficult to quantify. One might ponder, what counts as a more and what as a less distanced rhetorical configuration, especially given that the local degree zero is constantly shifting?

In the absence of a strict code that would allow for a strong correlation between plane of content and plane of expression, Groupe $\mu$ posits a pragmatic code, where the link is furnished by a given cultural practice and which determines the distance with regard to the norm that is instituted by a rhetorical transformation in the message. «In effect we are concerned with énoncés which are configured with regard to situations or realities external to the message» (Groupe $\mu$ 1992: 267) or embedded in cultural practices. "Thus, in this instance, we have another sort of isotopy, one furnished by culture» (Groupe $\mu$ 1992: 268). The compatibility between the two levels may be discerned by virtue of the redundancy of the énoncé, whereby one may diagnose the distance and proceed to its re-evaluation. «Redundancy is produced by the superimposition of various rules on the same unit of énoncé» (Groupe $\mu$ 1992: 265). Redundancy is a key operation, responsible for the maintenance of both verbal and visual isotopies, as put forward by Groupe $\mu$, following Greimas, in both Rhétorique Générale (1970) and the Traité (1992). As Sonesson (1996: 97) remarks, «redundancy is indeed the keyword of the Traité, where it is often made to do the job of isotopy itself». 


\section{Rhetoric as transformational syntax of multimodal brand communication}

Groupe $\mu$ distinguishes between two major modes of rhetorical transformation, that is homogeneous and heterogeneous. The fact that the primary field of application of Groupe $\mu$ 's visual rhetoric is art, and particularly visual art, does not mitigate the relevance of their insights and their potential transferability to branding discourse and its key manifestation of concern, viz. the ad filmic text. However, in order to facilitate this transferability, some parts of the conceptual account furnished by Groupe $\mu$ must be adjusted. Thus, the key distinction between homogeneous and heterogeneous transformations assumes as its point of reference the relationship of the iconic sign to the external referent. But at the same time it refers to the genre whereby the iconic rendition of an external referent is deemed as acceptable within specific cultural and sociohistorical contours. "Genre would seem to be an 'open-textured' concept, and genres are treated as 'fuzzy' categories, definable neither by necessary and sufficient conditions nor by fixed boundaries" (Bordwell 1989: 147). By extension, Bordwell argues that genres are enabling schemata, not deductive categories.

A homogeneous transformation maintains a non-deviant relationship between the iconic sign and the external referent, as against a heterogeneous transformation. Sonesson (2008b) rightly counter-argues that insofar as all rhetorical transformations entail artful deviation, the notion of homogeneity is not valid, while transformations can only be heterogeneous, as they bring about a relationship of otherness with the external referent. This particular argumentative thrust about rhetorical transformations has ontological leanings, which are not of direct relevance to self-referential branding discourse, in which context the local degree zero is more pertinent for understanding the notion of transformation.

In this context, a transformation may be homogeneous if it maintains isotopically a key aspect of a brand's master narrative and heterogeneous if it does not pertain directly to a dominant brand theme. The latter may also be termed as being of classematic (i.e. contextually semic, in Greimas's terms, which is also employed by Groupe $\mu$ ) nature, as it concerns context-specific sememes that are brought to bear by virtue of a rhetorical transformation on a brand's master narrative.

Through the operation of redundancy this new element either on the plane of expression or content, or both, may be ascribed the status of either a new element of a master brand narrative or a purely contextual one. In terms of the modalities involved in the ad filmic text, a further complication emerges due to the nature of the moving image and the sheer richness of imagery included in an ad film as against a static picture.

In the case of the ad filmic text, multiple rhetorical transformations are likely to be encountered. In this context, the meta-typologies of conjunction/disjunction in praesentia/absentia, proposed by Groupe $\mu$, may not be discerned within just a single frame or a single shot or even a single sequence. On the contrary, they often make sense only retrospectively, that is once the entire narrative has been deployed. Thus, there are two complications in transferring the various schemes proposed by Groupe $\mu$ to branding discourse, the first relating to the non-artistic nature of the pictures embedded in the context of advertising films and the second pertaining to the differences between the moving image and static pictures, which have been the province of Groupe $\mu$ 's analytical focus.

Thus, Sonesson's (2008b) remark about the proximity of two objects as being instrumental for the perception of an iconic object as one is not directly applicable to the gestalt of the filmic text, where visual signifiers, as Barthes notes, do not have just an anchoring, but also a relay function. An expressive unit in the context of the ad filmic text may consist of different shots from different sequences by virtue of the relay function of visual signifiers. This implies that the signified is postponed until these variably located signifiers will have been artificially juxtaposed. The same holds for rhetorical transformations effected through the relay function of visual signifiers. For example, even though in a single shot the juxtaposition of two visual signifiers may not be suggestive of a transformation; if one of them performs a relay function and requires exposure to a visual signifier from a later shot to make sense of a meaning derived from a transformation, then 
it is only by artificially reconstructing the manifest narrative of the ad filmic text that the function of a transformation may be discerned.

Increasing degree of deviation from the social norms of picture use

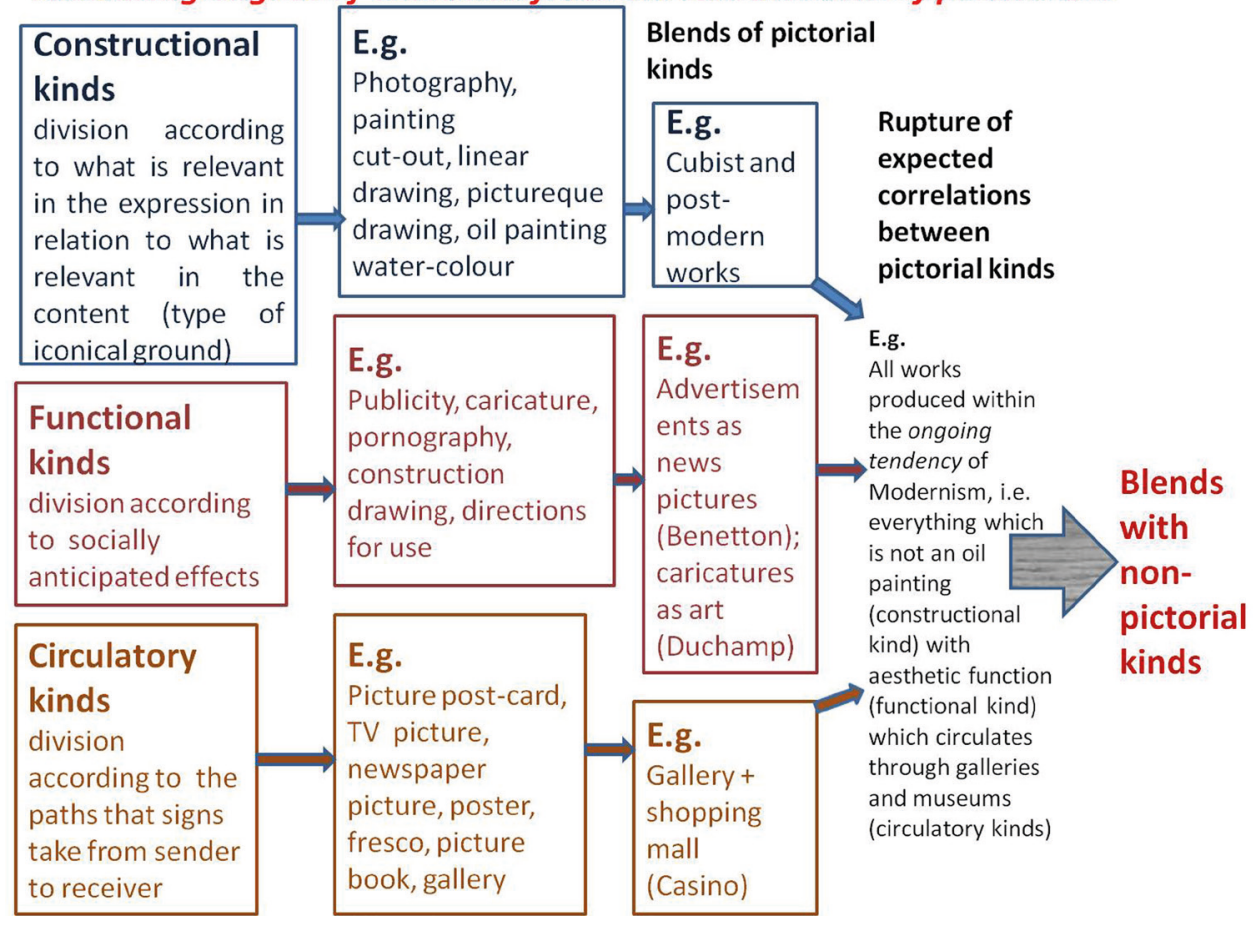

Figure 2. Different pictorial kinds based on their level of deviation from lifeworld norms (Sonesson 2008b: 27)

The above portrayal of rhetorical transformations and particularly with respect to the middle typology concerning functional pictorial discourse, may be complemented by a linkage not with 'socially anticipated effects', but with the brand discourse's internal semiotic structure or a brand's code, its idiolect (cf. Eco 1970: 23) and its specific way of maintaining brand identity through multiple ad texts. Not all elements in an advertising text are deviant with regard to generically defined social expectations or, in our case, with a target group's background expectations. The expectations of a target group with regard to the function of a brand discourse are occasionally conditioned by and instituted in the brand discourse, hence its idiolectal character. Additionally, insofar as brand discourse constitutes a gestalt of various correlations between elements of the planes of content and expression, reorienting what elements of the expression plane interconnect with corresponding elements of the content plane may be simply a matter of adopting a new style of communication, which does not conflict with an audience's expectations, but aims to maximize a brand's discursive differentiation from the competition. This is quite prominent in cases where either certain communicative codes or specific stylistic elements have become worn-out, which entails that they are minimally differentiating among brands.

The second point Sonesson (2010) makes, which may be contested, consists in his challenging Groupe $\mu$ 's standpoint on rhetorical transformations, which rests with a partial reading of the notion of transformation as 'rupture of isotopy' (Sonesson 2010), and his counterargument that it is not transformations that are rhetorical, but their combinations. This formulation seems to conflate the syntactical aspect of the notion of transformation and the semantic content of a rhetorical transformation. The reason is that a rhetorical operation is part of a combinatory logic, which defines the scope of possible semantic transformations. It is the combinatory logic as rhetorical syntax that allows for different combinations among signifiers. In this respect, combination and 
transformation are tautologous. In order for a string of signifiers to be transformed into a new expressive unit, they must be combined according to a given rationale and rhetoric furnishes this syntax that allows for combinations (Rossolatos 2012).

Regarding the narrow reading of Groupe $\mu$ 's notion of transformation as rupture of isotopy, it may be counter-argued that a rhetorical transformation is rupturous, but not necessarily of such a magnitude as to challenge a textual isotopy on a thematic level. At least this statement cannot be generalized, but must be qualified based on the genre, discourse and text at hand. For example, a stylistic transformation on the surface of a brand's discourse may consist of a rupture or a discontinuity, in terms of the stylistic codes of the genre or advertising style with which it is affiliated, but this rupture does not necessarily challenge the integrity of an underlying thematic structure. However, a rhetorical transformation may give rise to a radical reorientation of a key concept or brand image attribute in a brand's plane of content, hence it may bring about a thematic rupture.

Without going into greater detail as to specific semantic transformations brought about by multimodal rhetorical tropes and schemes, this section's main task was to demonstrate that the notion of meaning transformation should not be conceived in terms of a generic framework regarding either social expectations or a universal, non-genre specific homogeneous common ground. A rhetorical transformation should be conceived against the background of intra-brand and inter-brand communication codes, within a category-specific frame of reference.

A transformative rhetorical syntax of a brand's and category's discourse aims precisely at accounting for this moving degree zero, which is situational, context-specific and constantly shifting along with the multimodal enrichment of textual structures.

\section{Conclusions}

By drawing on structuralism, as well as visual and film semiotics, this paper aimed at casting a critical eye on rhetorical approaches that have been formulated, on the one hand, by consumer research and, on the other hand, by the cognitivist discipline, in relation to multimodal ad texts. Structuralist semiotics (of Greimasian persuasion) focuses on the differences between the morphology of signs and the syntactic aspects of the formation of a multimodal ad text, which occasionally are conflated in cognitivist approaches.

Furthermore, Groupe $\mu$ 's visual rhetorical approach, and particularly the concept of relative degree zero, is of paramount importance, as it imposes semiotic constraints on the frame of reference that allows for gauging a rhetorical operation as artful deviation. In this manner, it may contribute significantly to approaches in the consumer research literature, which have not addressed explicitly this matter.

Last, but not least, structuralist semiotics addresses how rhetorical transformations contribute to brand signification with respect to both content and expression planes, as against a unilateral focus on the latter, with which the concerned approaches in consumer research have been primarily preoccupied.

\section{Appendix 1- Hjelmslev's theory of the sign}

«The sign is an entity generated by the connection between an expression and a content» (Hjelmslev 1969: 47). Content and expression are designations of the functives that contract the sign function. «The sign function is in itself a solidarity. Expression and content are solidary- they necessarily presuppose each other» (Hjelmslev 1969:48). For Hjelmslev, content is the necessary correlate of expression, as functives in a sign function. In order to add further strength to this point, Hjelmslev employs the term 'purport', an allegedly cryptic notion, which has been multifariously interpreted in the relevant literature.

Despite the occasional inconsistencies in the employment of the term, it was primarily introduced in the Prolegomena in order to designate that 'amorphous thought mass' that constitutes the substance of content. Hjelmslev explicitly refrains from framing the concept in psychologi- 
cal or philosophical terms, while opting for retaining its ambiguity (even though disambiguation is a key principle of the glossematic theory). The reason why it is introduced is to point out the fact that even though in different languages the content of an expression may be rendered in different linguistic chains, the substance of the content as a sort of phenomenological intentional appropriation of the object to be described is the same, while varying in form. Thus, purport is the common denominator among various languages or the uniform content substance underpinning different forms of articulating content. "It is like the same handful of sand that is formed in different patterns $[\ldots]$ it has no possible existence except through being substance for some form or another" (Hjelmslev 1969: 52).

The relationship between content form and content substance, as purport, is arbitrary; yet substance depends on form for its morphing as such. In order to clarify the distinction between form and substance, as used by Hjelmslev, it might be useful to think of it in terms of two phases (for the sake of the argument and without implying any causal relationship between them), where in phase 1 one has an amorphous thought about a phenomenon, without being capable of articulating it, but having the purport or intentionality of articulating it. Once having acquired linguistic competency, one progressively manages to frame it in a conceptual form, thus articulating an initially amorphous thought substance into a coherent conceptual form. The conceptual form may differ among languages, depending on the arbitrary demarcation points used for framing the phenomenon conceptually (see the example on the classification of colors in Hjlemslev 1969: 53, also used by Greimas 1966: 26; also see Eco 1976), but the very intentionality or purport of framing as the substance of the form of content is uniform. By analogy, Hjelmslev splits the plane of expression as the other functive in a sign function into form and substance, where expression substance or purport is equivalent to the 'phonetic zones' of a language as elementary, pre-articulatory, in terms of meaningful form, expressive units and expression form the ultimately articulated into words purported substance. Thus, the sign, as the in-between of the sign function encompassing as functives the planes of content and expression, «is a two-sided entity, with a Janus-like perspective in two directions, and with effect in two respects: outwards towards the expression-substance and inwards towards the content-substance» (Hjelmslev 1969: 58).

\section{References}

Abbott, Don P. 2006: Splendor and misery: Semiotics and the end of rhetoric. In Rhetorica: A Journal of the History of Rhetoric 24.3, 303-323.

Barthes, Roland 1970: L'anciénne rhétorique. In Communications 16, 172-223.

Barthes, Roland 1977: Image-Music-Text. London: Fontana.

Bordwell, David 1989: Making Meaning: Inference and Interpretation in Cinema. Cambridge, Massachusetts: Harvard University Press.

Branigan, Edward 1992: Narrative Comprehension and Film. London: Routledge.

Carroll, John M. 1980: Toward a Structural Psychology of the Cinema. The Hague, Netherlands: Mouton.

Courtés, Joseph 1976 : Introduction à la Sémiotique Narrative et Discursive. Paris: Hachette.

De Rosia, Eric 2008: Rediscovering theory: Integrating ancient hypotheses and modern empirical evidence of the audience-response effects on rhetorical figures. In Mc Quarrie, E.F./Phillips, B.J. (eds.), Go figure: New Directions in Advertising Rhetoric. New York: M. E. Sharpe, 23-50.

Durand, Jacques 1970: Rhétorique et image publicitaire. In Communications 15, 70-95.

Durand, Jacques 1987: Rhetorical figures in the advertising image. In Umiker-Sebeok, J. (ed.), Marketing and Semiotics: New Directions in the Study of Signs for Sale. Berlin: Mouton de Gruyter, 295-318.

Eco, Umberto 1972: La Structure Absente. Paris: Mercure.

Eco, Umberto 1976: Theory of Semiotics. Bloomington, Indianapolis: Indiana University Press.

Eco, Umberto 1986: Semiotics and the Philosophy of Language. Bloomington, Indianapolis: Indiana University Press.

Floch, Jean M. 2001: Semiotics, Marketing and Communication. London: Palgrave Macmillan.

Forceville, Charles J. 1996: Pictorial Metaphor in Advertising. London: Routledge.

Forceville Charles J./Urios-Aparisi, Eduardo (eds.) 2009: Multimodal Metaphor. Berlin: Mouton. 
Gaine, Mike (ed.) 1993: Baudrillard Live: Selected Interviews. London: Routledge.

Greimas, Algirdas J. 1966: Sémantique Structurale. Paris: Presses Universitaires de France.

Greimas, Algirdas J. 1970: Du Sens I. Paris: Seuil.

Greimas, Algirdas J./Courtés, Joseph 1979: Sémiotique: Dictionnaire Raisonné de la Théorie du Langage. Paris: Hachette.

Greimas, Algirdas J. 1983: Du Sens II. Paris: Seuil

Greimas, Algirdas J. 1987: On Meaning. Minneapolis: University of Minnesota Press.

Greimas, Algirdas J. 1989a: The veridiction contract. In New Literary History 20.3, 651-660.

Greimas, Algirdas J. 1989b: Figurative semiotics and the semiotics of the plastic arts. In New Literary History 20.3, 627-649.

Groupe $\mu$ 1970: Rhétorique Générale. Paris: Larousse.

Groupe $\mu$ 1992: Traité du Signe Visuel: Pour une Rhétorique de l'image. Paris: Seuil.

Hebert, Louis 2011: Tools for Text and Image Analysis: An Introduction to Applied Semiotics [online]. www.signosemio.com.

Hjelmslev, Louis 1969. Prolegomena to a Theory of Language. London: University of Wisconcin Press.

Hjelmslev, Louis 1975: Resumé of a Theory of Language. London: University of Wisconcin Press.

Huhmann, Bruce A. 2008: A model of the cognitive and emotional processing of rhetorical works in advertising. In Mc Quarrie, E.F./Phillips, B.J. (eds.), Go figure: New Directions in Advertising Rhetoric. New York: M. E. Sharpe, 85-113.

Jakobson, Roman 1985: Closing statement: Linguistics and poetics. In Innis, R. (ed.), Semiotics: An Introductory Anthology. Indianapolis: Indiana University Press, 145-175.

Jeong, Se-Hoon 2008: Visual metaphor in advertising: Is the persuasive effect attributable to visual argumentation or metaphorical rhetoric? In Journal of Marketing Communications 14.1, 59-73.

Keller, Kevin L. 2008: Strategic Brand Management: Building, Measuring, and Managing Brand Equity. Upper Saddle River, New Jersey: Prentice-Hall.

Kenyon, Alexandra J./Hutchinson, Pollyanna L. 1997: Exploring rhetoric: Absolut and alcohol drinks advertisements. In British Food Journal 109.8, 594-607.

McQuarrie, Edward F./Mick, David G. 1992: On resonance: A critical pluralistic inquiry into advertising rhetoric. In Advances in Consumer Research 20, 309-313.

McQuarrie, Edward F./Mick, David G. 1996: Figures of rhetoric in advertising language. In Journal of Consumer Research 22.4, 424-438.

McQuarrie, Edward F./Mick, David G. 1999: Visual rhetoric in advertising: Text- Interpretive, experimental and readerresponse analyses. In Journal of Consumer Research 26.1, 37-54.

McQuarrie, Edward F./Mick, David G. 2003a: The contribution of semiotic and rhetorical perspectives to the explanation of visual persuasion in advertising. In Scott, L./Batra, R. (eds.), Persuasive Imagery: A Consumer Response Perspective. New Jersey: LEA, 191-221.

McQuarrie, Edward F./ Mick, David G. 2003b: Visual and verbal rhetorical figures under directed processing versus incidental exposure to advertising. In Journal of Consumer Research 29.4, 579-587.

McQuarrie, Edward/Phillips, Barbara 2004: Beyond visual metaphor: A new typology of visual rhetoric in advertising. In Marketing Theory 41.2, 113-136.

Messaris, Paul 1997: Visual Persuasion: The Role of Images in Advertising. London: Sage.

Metz, Christian 1982: The Imaginary Signifier. London: Macmillan.

Mick, David G. 1986: Consumer research and semiotics: Exploring the morphology of signs, symbols, and significance. In Journal of Consumer Research 13.2, 196-213.

Mick, David G./Buhl, Claus 1992: A meaning-based model of advertising experiences. In Journal of Consumer Research 19.3, 317-338.

Mick, David G. 1997: Semiotics in marketing and consumer research: Balderdash, verity, pleas. In Brown, S./Turley, D. (eds.), Consumer Research: Postcards from the Edge. London: Routledge, 249-262.

Nöth, Winfried 1990: Handbook of Semiotics. Indianapolis: Indiana University Press.

Philips, Barbara 2003: Understanding visual metaphor in advertising. In Scott, L./Batra, R. (eds.), Persuasive Imagery: A Consumer Response Perspective. New Jersey: LEA, 297-310.

Rossolatos, George 2012: Brand Equity Planning with Structuralist Rhetorical Semiotics Vol.I. Amazon Press. 
Scott, Linda 1994: Images in advertising: The need for a theory of visual rhetoric. In Journal of Consumer Research 21.2, 251-273.

Sonesson, Goran 1996: An essay concerning images: From rhetoric to semiotics by way of ecological physics. In Semiotica 109.1.2, 41-140.

Sonesson, Goran 2008a: Rhetoric from the standpoint of the lifeworld. Nouveaux Actes Sémiotiques. Actes de colloques (Le Groupe $\mu$, Quarante ans de rhétorique - Trente-trois ans de sémiotique visuelle).

Sonesson, Goran 2008b: Iconicity strikes back: The third generation - or why Eco still is wrong. Working paper, Lund University.

Sonesson, Goran 2010: La rhétorique des transformations homogénes - ou l'argumentation fondée sur la structure de la réalité Plenary speech at the 9th Congress of the International Association for Visual Semiotics, Venise, April 13 to $16,2010$.

Stam, Robert/Burgoyne, Robert/Flitterman-Lewis, Sandy 1992: New Vocabularies in Film Semiotics. London: Routledge.

St. Martin, Fernande 1987: Semiotics of Visual Language. Indianapolis: Indiana University Press.

Umiker-Sebeok, Jean (ed.) 1987: Marketing and Semiotics: New Directions in the Study of Signs for Sale. Berlin: Mouton de Gruyter.

Van Leeuwen, Theo /Kress, Gunther 2001: Multimodal Discourse: The Modes and Media of Contemporary Communication. London: Arnold.

Van Leeuwen, Theo 2005: Introducing Social Semiotics. New York: Routledge.

Van Mulken, Margot/Van Enschot, Renske/Hoeken, Hans 2008: Rhetoric in advertising: Attitudes towards verbo-pictorial rhetorical figures. In Information Design Journal 16, 35-46.

Van Mulken, Margot/Van Enschot, Renske/Beckers, Cyrella 2010: Rhetorical figures in TV commercials. In Information Design Journal 18.2, 138-147. 